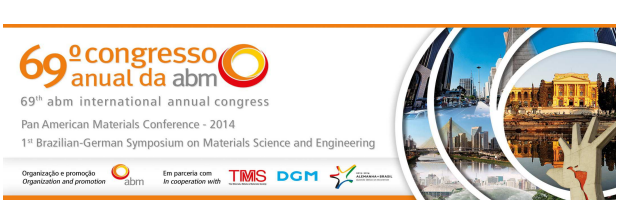

Tema: Produtos metálicos ferrosos

\title{
DESENVOLVIMENTO DE PLACAS DE AÇO API ATÉ X65, NA GERDAU OURO BRANCO, PARA TUBOS DE TRANSPORTE DE ÓLEO E GÁS*
}

\section{Resumo}

\author{
Gilberson Mendonça Storck de Melo ${ }^{1}$ \\ Alisson Paulo de Oliveira \\ Carlos Vinícius Domingos de Carvalho ${ }^{2}$ \\ Vinicius Cunha Aranda ${ }^{2}$ \\ Alvimar Paes Pinto Junior ${ }^{3}$ \\ Junior Sebastião Osório 4
}

O desenvolvimento de placas de aços API necessita de preparação adequada das etapas produtivas na aciaria, de maneira a garantir tanto o atendimento aos requisitos do cliente que irá laminá-las, como as condições da última edição da norma API 5L. Este trabalho contém as premissas e as ações tomadas para o desenvolvimento do processo, desde o vazamento até o processo de lingotamento, sempre com foco na qualidade da placa lingotada. Finalmente, serão mostrados os resultados de desempenho das placas, submetidas às premissas e condições de desenvolvimento, nos laminadores dos clientes.

Palavras-chave: Lingotamento contínuo de placas; Qualidade de placas lingotadas; Aços API; Processos de refino e lingotamento para aços API.

\section{DEVELOPMENT OF API STEEL SLABS, GRADES UP TO X65, AT GERDAU OURO BRANCO, FOR OIL AND GAS LINEPIPES}

\section{Abstract}

Development of API steel slabs demands suitable preparation of melt shop facilities, in order to ensure meeting of customer's requirements, as well as, the conditions stated on last edition of API 5L standard. This present work contains assumptions and actions have taken for process development, from ladle preparation to continuous casting process, always focusing on quality of cast slab. Finally, it will be shown performance results from slabs under those process development assumptions and actions at customers' mills.

Keywords: Continuous casting of slabs; Quality of cast slabs; API steel grades, Refining and casting processes for API steel grades.

1 Engenheiro Metalurgista, Assessor Técnico, Tecnologia de Processos e Produtos, Gerdau Aços Brasil, Usina Ouro Branco, Ouro Branco, MG, Brasil.

2 Engenheiro Metalurgista, Assessor Técnico, Facilitador de Melhoria, Lingotamentos Contínuos, Gerdau Aços Brasil, Usina Ouro Branco, Ouro Branco, MG, Brasil.

3 Técnico Metalurgista, Assessor Técnico, Facilitador de Melhoria, Lingotamentos Contínuos, Gerdau Aços Brasil, Usina Ouro Branco, Ouro Branco, MG, Brasil.

4 Técnico Metalurgista, Técnico em Desenvolvimento de Produtos, Tecnologia de Processos e Produtos, Gerdau Aços Brasil, Usina Ouro Branco, Ouro Branco, MG, Brasil.

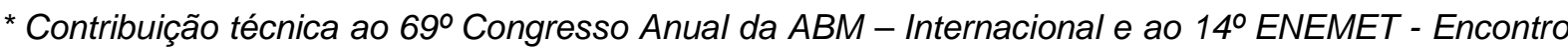
Nacional de Estudantes de Engenharia Metalúrgica, de Materiais e de Minas, 21 a 25 de julho de 2014, São Paulo, SP, Brasil.
} 


\section{INTRODUÇÃO}

As exigências do mercado, normalmente, acompanham as necessidades e demandas tecnológicas de aplicação de produtos, e que por sua vez, necessitam de processos cada vez mais apurados para produzi-los. Nesta linha caminham, também, os processos siderúrgicos de refino e lingotamento necessários para a produção dos graus de aço da norma API 5L. As exigências, a severidade das aplicações e usos finais têm crescido com o passar dos anos [1,2], e para sustentar esta situação, têm sido largamente utilizados processos de refino que conferem maior limpidez, e práticas de lingotamento que consigam menores índices de segregação e trincas internas.

A limpidez dos aços utilizados para transporte de óleo e gás é fundamental para o desempenho da tubulação. Com o passar dos anos, os processos de aciaria que provocaram grande diminuição nos teores dos principais elementos residuais foram desenvolvidos e consolidados. A remoção de impurezas no aço, principalmente a do enxofre, foi importantíssimo para a tenacidade destes aços, principalmente em ambientes ácidos. As Figuras 1a e 1b demonstram esta evolução histórica.
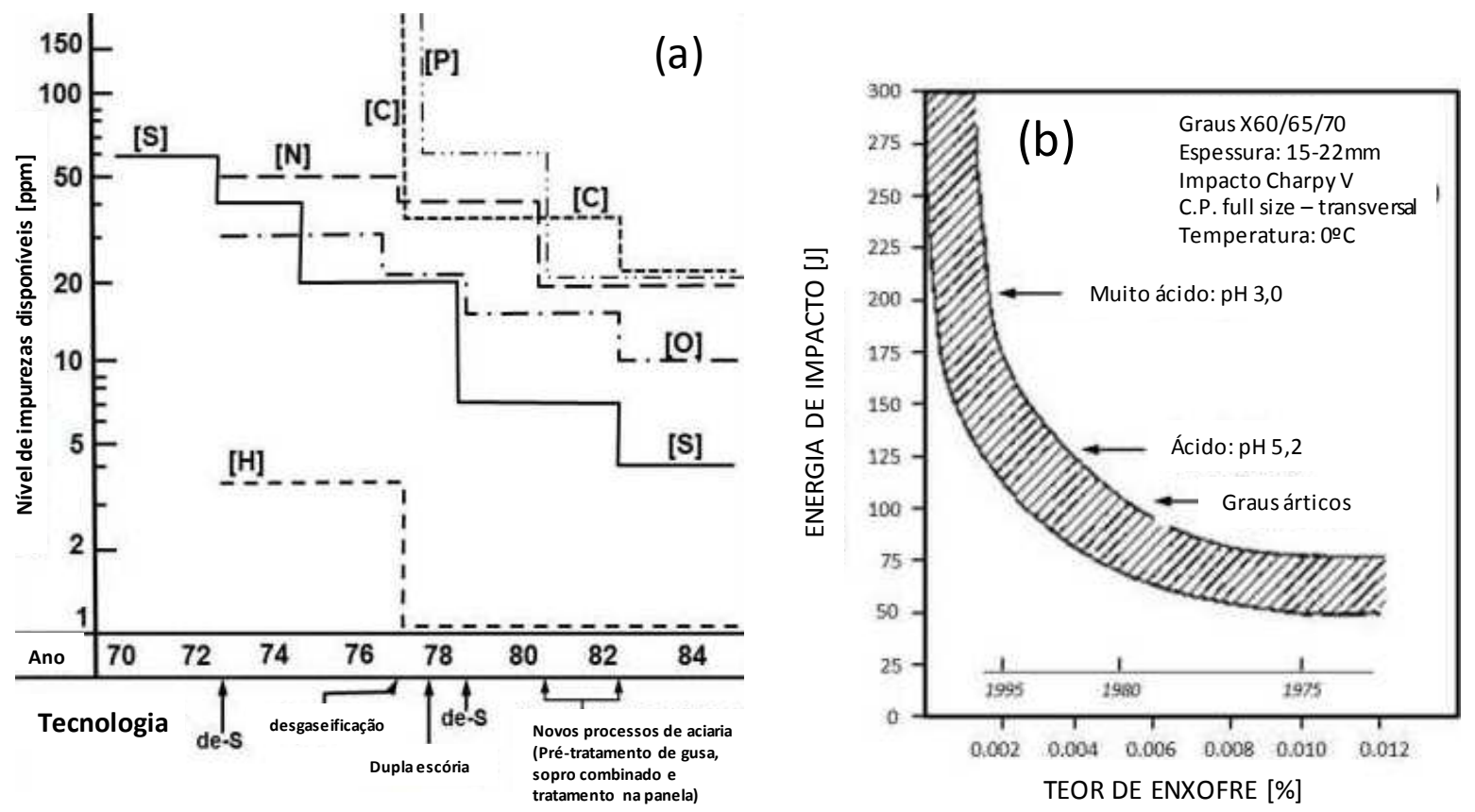

Figura 1. Evolução histórica do nível de impureza dos aços (a). Evolução do teor de enxofre (b) [2].

Avanços no processo de lingotamento, tais como, o desenvolvimento dos rolos dos segmentos tripartidos, soft-reduction dinâmico, leitura dos intervalos entre rolos superior e inferior dos segmentos (gap) e melhor possibilidade de ajuste e controle do gap trouxeram melhorias significativas nas características de qualidade interna das placas $[3,4]$. Uma vez que muitos laminadores especificam e monitoram a qualidade interna de sua matéria-prima, é importante garantir que estas funcionalidades estejam operando adequadamente, maximizando a qualidade interna do material lingotado.

Além de toda tecnologia desenvolvida no refino dos aços, e embarcada em máquinas de lingotamento, é fundamental ter o controle das variáveis críticas do processo de lingotamento. Normalmente, os aços para transporte de óleo e gás apresentam-se como peritéticos (C: $0,08 \%$ - 0,15\%) microligados ao $\mathrm{Nb}, \mathrm{V}, \mathrm{Ti}$

\footnotetext{
* Contribuição técnica ao 69 Congresso Anual da ABM - Internacional e ao 14ํㅡㄹ ENEMET - Encontro Nacional de Estudantes de Engenharia Metalúrgica, de Materiais e de Minas, 21 a 25 de julho de 2014, São Paulo, SP, Brasil.
} 


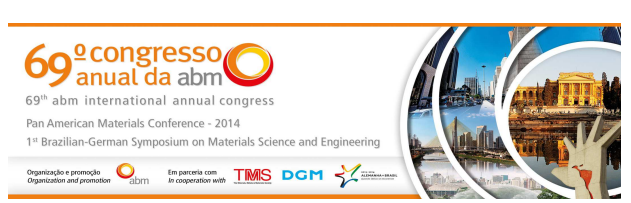

combinados ou não. De acordo com Wolf [5], Super Heat, velocidade de lingotamento e refrigeração secundária seriam as variáveis a serem controladas de maneira a evitar trincas superficiais e sub superficiais [6,7] às quais devem ser removidas por escarfagem manual.

\section{MATERIAIS E MÉTODOS}

\subsection{Metodologia de Gerenciamento}

O desenvolvimento de placas para venda a clientes, na Gerdau - Unidade Ouro Branco, segue a metodologia de gerenciamento PDCA, onde as macro-etapas $P$ (Plan - planejamento), D (Do - execução), C (Check - verificação) e A (Action agir) são adaptadas para gerenciar as etapas de desenvolvimento de produtos, conforme mostrado na Figura 2.

\begin{tabular}{|c|c|l|}
\hline \multicolumn{2}{|c|}{ ETAPAS PDCA } & \multicolumn{1}{|c|}{ ESTRATÉGIAS } \\
\hline \multirow{4}{*}{ P } & P1 & ESTUDO DE VIABILIDADE TÉCNICA \\
\cline { 2 - 3 } & P2 & PROJETO DE PRODUTO \\
\cline { 2 - 3 } & P3 & PROJETO DO PROCESSO \\
\hline \multirow{2}{*}{ D } & D1 & EXECUÇÃO DO PROJETO DE PROCESSO \\
\hline \multirow{2}{*}{ C } & C1 & $\begin{array}{l}\text { ANÁLISE DO PRODUTO E PROCESSOS } \\
\text { PRODUTIVOS }\end{array}$ \\
\cline { 2 - 3 } & C2 & $\begin{array}{l}\text { VERIFICAÇÃO DOS RESULTADOS DE } \\
\text { DESEMPENHO DO PRODUTO NO CLIENTE }\end{array}$ \\
\hline \multirow{3}{*}{ A } & A1 & VALIDAÇÃO DO PROJETO DE PRODUTO \\
\cline { 2 - 3 } & A2 & PADRONIZAÇÃO DAS VARIÁVEIS DE PROCESSO \\
\hline
\end{tabular}

Figura 2. Fluxo adotado na Gerdau Ouro Branco para desenvolvimento de produtos.

Aplicando a definição clássica da etapa $\mathrm{P}$ (Plan - planejamento) [8] para o caso de desenvolvimento de produtos, a viabilidade técnica da produção é o ponto de partida. Esta análise é realizada sempre em conjunto com os responsáveis pelo processo das etapas produtivas: refino e lingotamento. No caso de um parecer positivo, é elaborado o projeto do produto, com o estabelecimento de todas as especificações de cliente a serem atingidas. Os procedimentos operacionais são avaliados e revisados, quando necessário, compondo o projeto de processo que será empregado na produção das placas de aço.

As macro-etapas $\mathrm{D}$ (Do - execução), e C (Check - verificação) serão discutidas na secção 3 "RESULTADOS E DISCUSSÕES".

\subsection{Projeto de Processo}

O projeto de processo para placas de aço API para tubos de transporte de óleo e gás, tradicionalmente [9], envolve elaboração do aço através de convertedor LD, refino de panela, desegaseificação e lingotamento contínuo, conforme descrito na Figura 3 abaixo.

* Contribuição técnica ao $69^{\circ}$ Congresso Anual da ABM - Internacional e ao 14ํㅡㄹ ENEMET - Encontro Nacional de Estudantes de Engenharia Metalúrgica, de Materiais e de Minas, 21 a 25 de julho de 2014, São Paulo, SP, Brasil. 

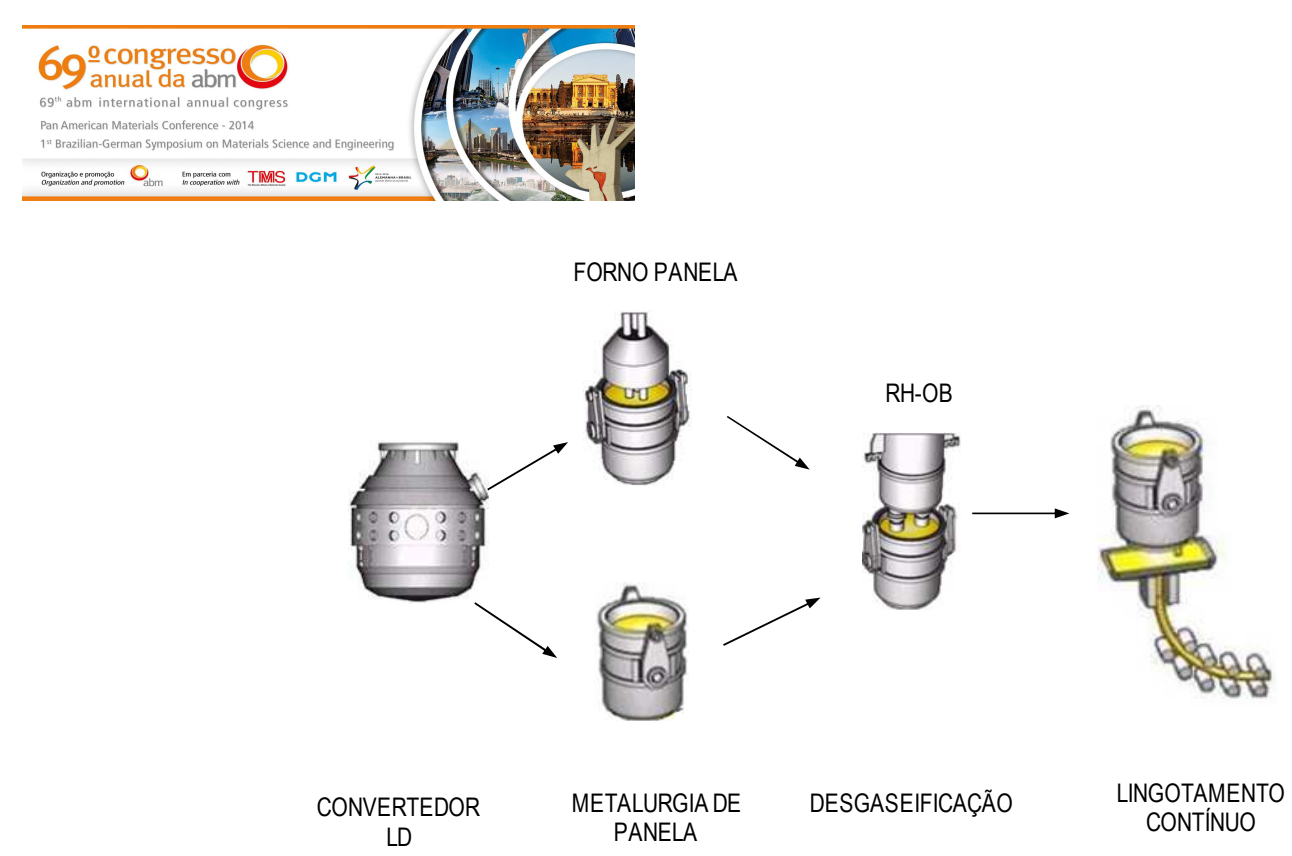

Figura 3. Esquema simplificado do projeto de processo.

$\mathrm{Na}$ etapa de metalurgia de panela, busca-se obter a limpidez do banho metálico através de ações que irão permitir a dessulfuração do aço e a desoxidação da escória sobrenadante. Na desgaseificação, como objetivo primário, busca-se obter teores de hidrogênio menores ou iguais a 3ppm, além de adicionar Ca-Si para modificação da morfologia das inclusões. Para o lingotamento, procura-se conseguir índices de trincas internas e segregação central menores ou iguais a 2 no padrão Mannesmann de qualidade.

\subsubsection{Metalurgia de panela}

Conforme mostrado na Figura 3, a metalurgia de panela é uma etapa com duas opções, onde são realizadas as adições de ligas e fundentes em panela sem ou com aquecimento (utilizando Forno Panela), onde são objetivadas a dessulfuração do aço e a desoxidação da escória sobrenadante.

Escórias sintéticas são adicionadas durante o vazamento do aço do convertedor LD para a panela, ou no próprio Forno Panela, permitindo a realização da dessulfuração e desoxidação simultaneamente. A realização de ambos tratamentos vai depender do teor de $\mathrm{CaO}$, alumina, ou alumínio metálico contido no insumo. Uma vez adicionada, já na fase líquida, a escória absorve as inclusões sólidas de alumina contidas no aço, transformando-as em aluminatos de cálcio líquidos.

Maiores teores de $\mathrm{CaO}$ conferem aumento da basicidade e fluidez, além de uma alta dispersão e superfície de contato, as quais são condições favoráveis para a dessulfuração.

Gavanescu [10] reporta que cerca de metade dos teores de enxofre e oxigênio foram removidos utilizando escórias sintéticas baseadas em aluminatos de cálcio, com 51 $-56 \%$ de $\mathrm{CaO}$, onde os teores médios para ambos elementos, após tratamento, são $35 p p m$ para enxofre e 20ppm para oxigênio. O desempenho da deoxidação também pode ser medido, indiretamente, pelo teor combinado de $\mathrm{FeO}+\mathrm{MnO}$ na escória sobrenante de forno panela [11,12], onde a soma conseguida está por volta de $2,50 \%$ após tratamento com escórias sintéticas com teores entre $50-60 \%$ de CaO.

\subsubsection{Desgaseificação}

A função principal da desgaseificação é a utilização de vácuo para a exaustão dos gases $\mathrm{CO}, \mathrm{H}_{2}$ e $\mathrm{N}_{2}$, que estão dissolvidos no aço na forma de carbono, hidrogênio e nitrogênio. Por ser um ambiente com alta turbulência, a aglomeração e flutuação das

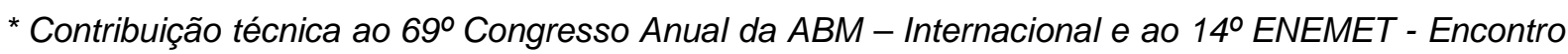
Nacional de Estudantes de Engenharia Metalúrgica, de Materiais e de Minas, 21 a 25 de julho de 2014, São Paulo, SP, Brasil.
} 
inclusões é favorecida, sendo, assim, possível de se produzir aços com altos níveis de limpidez.

$\mathrm{Na}$ usina Ouro Branco, o equipamento utilizado para desgaseificação é o $\mathrm{RH}-\mathrm{OB}$, o qual é dotado com uma lança de oxigênio (O.B.: Oxygen Blowing), o que confere uma excelente descarburação, além de permitir aquecimento químico do banho por aluminotermia (calor gerado pela oxidação do alumínio e transferido para o banho).

Adicionalmente, é realizado tratamento com cálcio, adicionando fio de aço oco preenchido por grânulos de CaSi, o que permite uma penetração eficiente no banho. O cálcio dissolvido no banho permite a mudança de composição e morfologia das inclusões sólidas. Uma capa formada por sulfetos de cálcio e manganês envolve inclusões sólidas de aluminatos de cálcio, conforme mostrado na figura 4, formando assim glóbulos que irão flotar para a escória sobrenadante. Como consequência deste processo, excelentes resultados [13,14] têm sido alcançados, como, por exemplo, a obtenção de um teor médio de enxofre de $20 \mathrm{ppm}$ com desvio padrão de 3ppm [14].

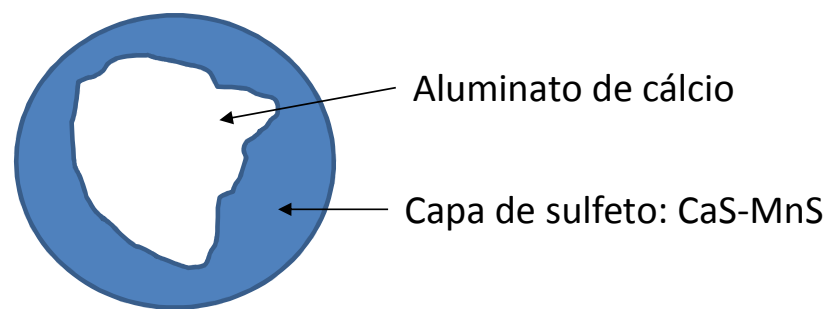

Figura 4. Esquema de glóbulo formado por aluminato de calcio envolvido por capa de sulfetos.

\subsubsection{Lingotamento contínuo}

A etapa de lingotamento contínuo, além de dar a forma desejada, pode ser considerada como a última etapa de realização de tratamentos metalúrgicos. Uma boa prática de metalurgia de distribuidor significa evitar a contaminação do banho pelo ar atmosférico, evitar perda excessiva de temperatura e permitir a flotação de inclusões não metálicas.

Geralmente, os projetos de liga de aços API até X65, para transporte de óleo e gás, têm sido formados por aços baixo carbono (C: $0,02 \%-0,07 \%)$ ou peritéticos (C: $0,08 \%-0,15 \%$ ), médio manganês ( $\mathrm{Mn}: 1,00 \%-1,50 \%)$ microligados a um ou mais dos seguintes elementos: $\mathrm{Nb}, \mathrm{Ti}, \mathrm{V}$. Esta classe de aço necessita ter um controle rigoroso de suas variáveis de processo, tais como: Super Heat, velocidade de lingotamento, transferência de calor no molde e refrigerações primária (molde) e secundária, de maneira a obter uma boa qualidade de superfície, evitando trincas superficiais e sub-superficiais.

Super Heat e velocidade de lingotamento normalmente são variáveis consideradas em conjunto na operação da máquina de lingotamento. Jansto [15] verificou que temperaturas entre $20^{\circ} \mathrm{C}$ e $25^{\circ} \mathrm{C}$ e velocidades otimizadas (5-10\% maiores) obtevese um cenário de maior ductilidade (maiores valores de redução de área em situações com maiores taxas de deformação) podendo, assim, evitar o aparecimento de trincas superficiais e sub-superficiais.

A diminuição da transferência de calor no molde é fator chave para se conseguir boa qualidade de superfície. Uma maneira largamente utilizada é o desenvolvimento de pós fluxantes específicos que geram uma camada espessa de escória de pó cristalina entre a pele e o molde [16]. Milosavljevic et al.[17] desenvolveram um método de refrigeração primária que garante níveis menores que $1,0 \mathrm{MW} / \mathrm{m}^{2}$ de

\footnotetext{
* Contribuição técnica ao $69^{\circ}$ Congresso Anual da ABM - Internacional e ao 14ํㅡㄹ ENEMET - Encontro Nacional de Estudantes de Engenharia Metalúrgica, de Materiais e de Minas, 21 a 25 de julho de 2014, São Paulo, SP, Brasil.
} 
calor transferido para face larga do molde, e com isso, praticamente eliminaram trincas superficiais.

Aspectos mecânicos da máquina de lingotamento, tais como alinhamento dos rolos superior e inferior dos segmentos (gap), vida dos rolos e funcionamento correto do soft reduction são importantíssimos para a qualidade interna das placas. $O$ desalinhamento excessivo do gap e o espaçamento horizontal inadequado entre rolos (roll pitch), bem como suas associações com trincas internas, foram estudadas por Triolet et al. [18], que modelaram o comportamento mecânico do veio em situações de abaulamento da face larga (bulging), onde a frente de solidificação, sob comportamento viscoplástico, sofreram solicitações alternadas de tensão e compressão.

As trincas internas são classificadas conforme o conhecido, e largamente utilizado, padrão Mannesmann de qualidade, onde amostras após ataque químico revelam trincas e segregação central, onde os menores valores das características significam melhores valores. Estas trincas podem significar microsegregação de impurezas tais como fósforo e enxofre, e são extremamente prejudiciais à aplicação como tubo de transporte de óleo e gás.

\section{RESULTADOS E DISCUSSÃO}

Seguindo a metodologia de gerenciamento de projetos, onde a macro-etapa P (Plan - planejamento) foi descrita no item anterior, e, uma vez que o processo foi executado conforme projeto (macro-etapa: D (Do - execução)), neste tópico serão mostrados resultados de desempenho de processo e qualidade do produto (macroetapa C (Check - verificação)), com foco na dessulfuração e na remoção de hidrogênio.

\subsection{Dessulfuração}

$\mathrm{Na}$ etapa de metalurgia de panela, foi realizada a adição de uma escória sintética, durante o vazamento do aço, do convertedor LD para a panela, buscando a realização da dessulfuração, na Tabela 1 é apresentada a composição deste insumo.

Tabela 1. Composição especificada da escória sintética adicionada durante vazamento

\begin{tabular}{lc} 
Material & {$[\%]$} \\
\hline $\mathrm{CaO}$ & $55-65$ \\
\hline $\mathrm{Al}_{2} \mathrm{O}_{3}$ & $9-14$ \\
\hline $\mathrm{Al}_{\text {metálico }}$ & $6-10$ \\
\hline $\mathrm{CaF}_{2}$ & $6-10$ \\
\hline $\mathrm{SiO}_{2}$ & 4 max. \\
\hline $\mathrm{MgO}$ & 7 min. \\
\hline
\end{tabular}

Adicionalmente, na etapa desgaseificação, após os tratamentos com vácuo e correção química, é realizada a adição de $600 \mathrm{~m}$ de $\mathrm{Ca}-\mathrm{Si}$ em fio, com o objetivo de globulizar inclusões para flotação (previamente discutido no item 2.2.2).

Abaixo, a Figura 5 mostra os resultados do desempenho da dessulfuração de aço API X60 utilizando escória sintética, em comparação com outro grau de aço estrutural que possui tratamento com cálcio, através da adição de CaSi, mas não é utilizado o tratamento com escória sintética.

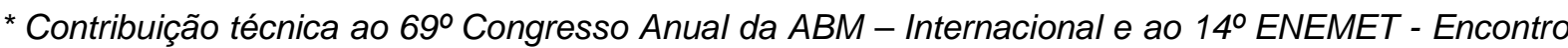
Nacional de Estudantes de Engenharia Metalúrgica, de Materiais e de Minas, 21 a 25 de julho de 2014, São Paulo, SP, Brasil.
} 


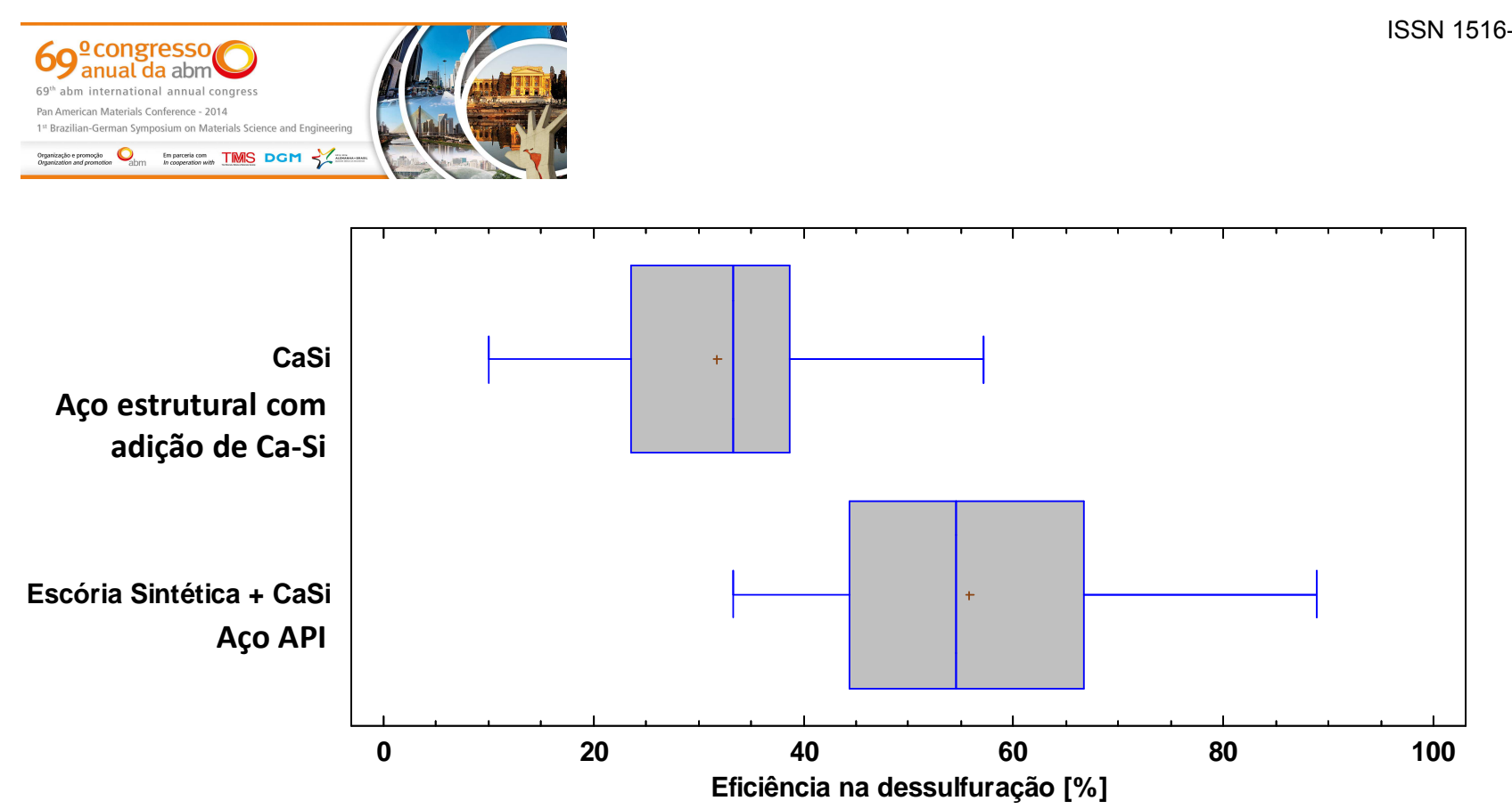

Figura 5. Comparação da eficiência da dessulfuração em relação às práticas de dessulfuração para aço API (Escória sintética + CaSi) e aço estrutural (apenas com adição de CaSi).

Percebe-se que o comportamento do tratamento com ambos agentes (Escória sintética + CaSi) é mais efetivo, uma vez que seus piores resultados se equivalem à média e mediana do tratamento apenas com CaSi.

\subsection{Desgaseificação - Retirada de Hidrogênio e Pick-up}

De maneira a medir, tanto o processo de desgaseificação, como a manutenção de baixos teores de hidrogênio dissolvido no aço, foram realizadas medidas na desgaseificação, após término do vácuo e no distribuidor, após lingotamento de metade da carga de panela.

O hidrogênio dissolvido no aço, após a término do vácuo, nunca excede a 2ppm, e raramente iguala a este valor. Os valores no distribuidor, bem como o pick-up estão coerentes com aqueles obtidos por outros autores [19-21].

\subsection{Qualidade das Placas}

\subsubsection{Qualidade de superfície}

Considerando que os aços produzidos são totalmente peritéticos (C: 0,08\% - 0,15\%) ou estão na fronteira no que é considerado aço baixo carbono com peritéticos $(\mathrm{C}$ : $0,06 \%-0,07 \%$ ) é realizada uma gestão das variáveis de processo visando diminuir os efeitos deletérios da transformação peritética. Os índices de recondicionamento obtidos após inspeção foram de $2,54 \%$ para os aços na fronteira entre BC e peritéticos, e 3,59\% para os aços totalmente peritéticos.

Os bons resultados obtidos no índice de recondicionamento são devidos aos valores de Super Heat alcançados, bem como a otimização das velocidades de lingotamento para ambos os aços, tal como descrito por Jansto [15].

Com relação aos aços totalmente peritéticos, os resultados são coerentes com as premissas apresentadas pelos autores $[16,17]$ que afirmam que o lingotamento com transferência de calor no molde mais suave resulta em uma melhor qualidade de superfície, conforme mostrado na Figura 6.

\footnotetext{
* Contribuição técnica ao 69ำ Congresso Anual da ABM - Internacional e ao 14ํㅡㄹ ENEMET - Encontro Nacional de Estudantes de Engenharia Metalúrgica, de Materiais e de Minas, 21 a 25 de julho de 2014, São Paulo, SP, Brasil.
} 

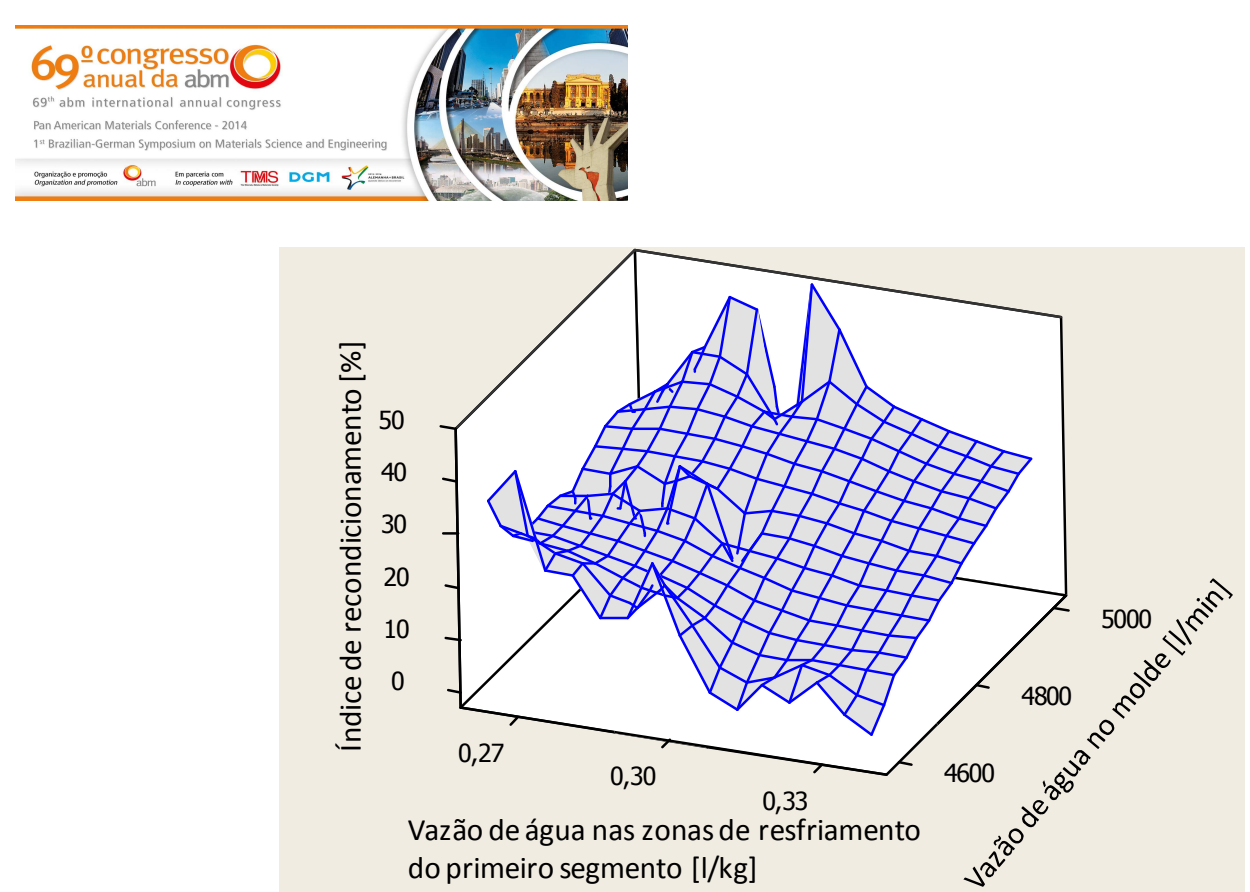

Figura 6. Relação entre índice de recondicionamento com a vazão de água no molde e no resfriamento secundário para aço API X65 totalmente peritético.

Embora seja preferido um fluxo de calor baixo e uniforme, a pele fina e homogênea formada não possui resistência suficiente para resistir às sucessivas contrações e expansões da transformação peritética, causando refluxo de líquido em direção ao molde, através do chamado efeito acordeão [21]. Este fato aumenta fortemente a instabilidade no menisco, causando a formação de trincas longitudinais no molde. Logo, deve-se buscar a otimização da refrigeração secundária, aumentando a espessura de pele homogênea formada, evitando o efeito acordeão e a formação de trincas no molde por efeito retardado, devido à instabilidade no menisco.

\subsubsection{Qualidade interna}

A qualidade interna da placa é um item de especificação que influencia fortemente na qualidade do tubo. A Figura 7 mostra amostras de macro-ataque característica para aços classificados como API X60. Percebe-se que as amostras: esquerda, centro e direita são homogêneas, e praticamente não possuem diferenças entre si. Foi atribuído o índice 1 (melhor) para todas as características, exceto para segregação central, atribuída como 2.

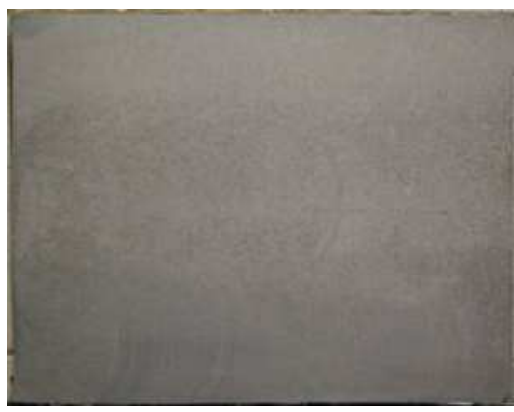

ESQUERDA

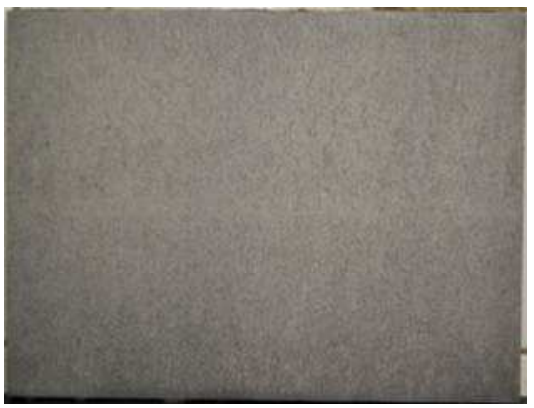

CENTRO

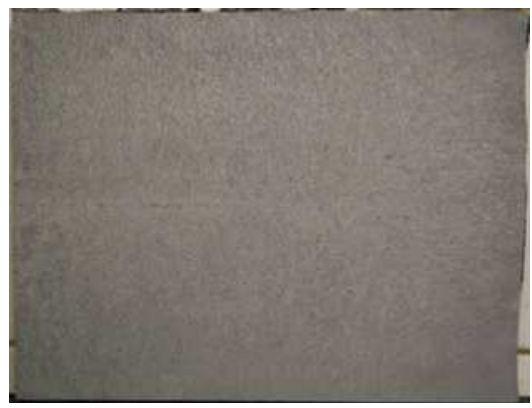

DIREITA

Figura 7. Amostras de macro-ataque típicas de placas de aços API X60.

Toda a produção avaliada apresentou no ensaio de macro-ataque, classificação menor ou igual a 2 no padrão Mannesmann de qualidade interna.

\footnotetext{
* Contribuição técnica ao 69ำ Congresso Anual da ABM - Internacional e ao 14ํㅡㄹ ENEMET - Encontro Nacional de Estudantes de Engenharia Metalúrgica, de Materiais e de Minas, 21 a 25 de julho de 2014, São Paulo, SP, Brasil.
} 


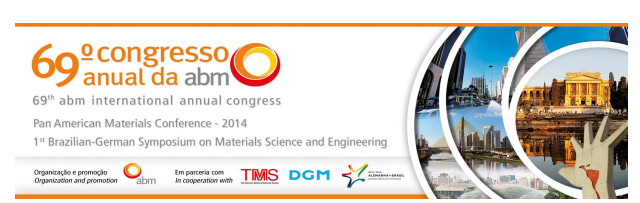

A segregação central é um item inerente ao processo de solidificação no lingotamento contínuo, onde não é possível a isenção desta característica, e normalmente, para tubos de transporte de óleo e gás, o nível 2 é tolerado. O menor nível das demais características de trinca significa que o veio não sofreu grandes solicitações mecânicas durante o lingotamento, resultando em uma ótima sanidade interna, e ficando livre de possíveis pontos de microssegregação.

\subsubsection{Desempenho das placas no cliente}

Como última parte da macro-etapa C (Check - verificação), a medição do desempenho das placas fornecidas nos laminadores do cliente foi realizada. Com os resultados apresentados pelo cliente, a macro-etapa $A$ (Action - agir) foi realizada. Assim, o projeto de processo foi validado e todas as variáveis de processo padronizadas.

$\mathrm{Na}$ Tabela 2, são contabilizados aspectos de qualidade do produto laminado e do processo de produção do tubo que são diretamente influenciados pela limpidez do aço e qualidade das placas.

Tabela 2. Resultados dos principais itens de qualidade do produto laminado e do tubo

\begin{tabular}{lc}
\hline Característica de qualidade & {$[\%]$} \\
\hline Defeito de superfície no laminado* $^{*}$ & 0,13 \\
\hline Recusa no Crush Test ${ }^{\star *}$ & 0,06 \\
\hline Recusa no teste hidrostático & 0,00 \\
\hline $\begin{array}{l}\text { Porção dúctil < 85\% na secção de } \\
\text { fratura do C.P. charpy V 0C. }\end{array}$ & 0,00 \\
\hline $\begin{array}{l}\text { Qualquer tipo de recusa causada por } \\
\text { inclusões não metálicas. }\end{array}$ & 0,00 \\
\hline
\end{tabular}

* causado pelo afloramento de trincas, macro-inclusões, pó fluxante, ou qualquer outro elemento sub-superficial. **teste de compressão na direção normal do cordão de solda.

\section{CONCLUSÃO}

O processo desenvolvido para a produção de placas de aço API até X65 atenderam aos requisitos de qualidade exigidos devido ao foco dado à limpidez do aço e às qualidades interna e de superfície.

O tratamento com dois agentes dessulfurantes foi fundamental na eficiência de remoção do enxofre, o que, consequentemente, resultou em uma produção de tubos livre de recusas por qualquer descontinuidade relacionada a sulfetos.

$\mathrm{O}$ atendimento às variáveis de processo de lingotamento, visando baixo fluxo de calor no molde e fortalecimento da pele para evitar o efeito acordeão, foram decisivos nos resultados de qualidade de superfície alcançados.

\section{REFERÊNCIAS}

1 Belato Rosado D, Waele W, Vanderschueren D, Hertelé S. Latest developments in mechanical properties and metallurgical features of high strength line pipe steels. Sustainable Construction and Design. 2013; 4(1):11-20.

2 Malcom Gray J, Siciliano F. High strength microalloyed linepipe: half a century of evolution. China International Symposium on the 30th anniversary of niobiumcontaining steel technology. 2009; 20-43.

\footnotetext{
* Contribuição técnica ao $69^{\circ}$ Congresso Anual da ABM - Internacional e ao 14ํㅡㄹ ENEMET - Encontro Nacional de Estudantes de Engenharia Metalúrgica, de Materiais e de Minas, 21 a 25 de julho de 2014, São Paulo, SP, Brasil.
} 
3 Xiao C, Zhang J, Luo Y, Lian W, Wang S. Optimization investigation on the soft reduction parameters of medium carbon steels. Materials Processing. 2013; 9(4): 109118.

4 Wolf M. Initial solidification and strand surface quality of peritectic steels. Warrendale: ISS; 1987.

5 Park YK, Baek SK. Revamping of the No.1-3 slab caster at Posco Gwangyang: design, start-up and first results. Revue de Métallurgie. 2004; 101(6): 467-472.

6 Mazumdar S, Ray SK. Solidification control in continuous casting of steel. Sadhana. $2001 ; 26(1) ; 179-198$.

7 Carpenter K. The influence of microalloying elements on the hot ductility of thin slab cast steek [PhD]. Wollongong: University of Wollongong; 2004.

8 Campos VF. Controle de qualidade total (no estilo japonês). Belo Horizonte: Fundação Christiano Otoni; 1992.

9 Palmer AC, King AR. Subsea pipeline engineering. Tulsa: Pennwell; 2004.

10 Gavanescu A. Refining of steel by using synthetic slag. Annals of faculty engineering Hunedoara - International Journal of engineering. 2011; 9(Extra): 177-179.

11 Zhang L, Thomas BG. State of the art in evaluation and control of steel cleanliness. 2003; 43(3): 271-291.

12 Mayowa SF. Improvement of desulphurisation process by slag composition control in the ladle furnace [MSc.]. Lulea: Lulea University of Technology; 2009.

13 Hollappa L, Hmlinen M, Liukkonen M, Lind M. Thermodynamic examination of inclusion modification and precipitation from calcium treatment to solidified steel. Ironmaking and steelmaking. 2003; 30(2): 109-117.

14 Colombert L, Sancho L, Schaffer B. Steel desulfurization at Sollar Dunkirk. In: McPherson NA, McLean A, Non metallic inclusion in continuously cast steels. Warrendale: ISS: 113-117.

15 Jansto SG. Steelmaking and continuous casting process metallurgy factors influencing hot ductility behavior of niobium bearing steels. $22^{\text {nd }}$ International Conference on Metallurgy and Materials. 2014. [acesso em 05/04/2014]. Disponível em http://www.metal2014.com/files/proceedings/12/reports/1376.pdf.

16 Thomas BG, Dziuba M, DiGresia. Study of cc narrow-face tapered design - influence of the casting speed and steel composition. $14^{\text {th }}$ IAS Steelmaking Conference Proceedings. 2003. $87-95$.

17 Milosavljevic N, Slovic Z, Bradaric T. Soft cooled mold for continuous casting of slabs. $23^{\text {rd }}$ International Conference on Metallurgy and Materials. 2014. [acesso em 05/04/2014]. Disponível em http://www.metal2014.com/files/proceedings/metal_00/papers/119.pdf

18 Triolet N, Bobadilla M, Bellet M, Avedian L, Mabelly P. A thermalmechanical modeling of continuous casting to master steel slabs internal soundness and surface quality. La Revue de Mètallurgie. 2005; 102(5): 343-353.

19 Misra S, Li Y, Sohn I. Hydrogen and nitrogen control in steelmaking at U.S. steel. [acesso em 10/04/2014]. Disponível em http://www.electronite.de/media/webmedia_local/media/downloads/steel_2/hydrogenandnitrogen/hydroge nnitrogencontrolatuss.pdf

20 Chen C-Y, Lin K-J. Forming factors of blowhole defect in continuously cast beam blank at Dragon Steel. China Steel Technical Report. 2011; 24(1): 7-13.

21 Sumitomo Metals Industries Ltd. Development of high efficiency continuous casting technologies. [acesso em 10/04/2014]. Disponível em http://www.nssmc.com/en/news/old_smi/2008/news2008-10-16-02.html

\footnotetext{
* Contribuição técnica ao 69 Congresso Anual da ABM - Internacional e ao 14ํㅡㄹ ENEMET - Encontro Nacional de Estudantes de Engenharia Metalúrgica, de Materiais e de Minas, 21 a 25 de julho de 2014, São Paulo, SP, Brasil.
} 